\title{
Assessing Motives in Northeast Asian Aid Allocations: China, Japan, and Korea as a Collective Group and as Individual Donors
}

\author{
Hyuk-Sang Sohn, Seokwoo Kim, and Changbin Woo
}

The landscape of global foreign aid is changing with the growing number of new donors, especially in Asia. While Japan is no longer overwhelmingly dominant, complexity grows as China is becoming increasingly influential as an emerging donor, and Korea is rising to be a considerable donor by joining the OECD's Development Assistance Committee. In this context, there have been numerous controversies concerning East Asian donors, and even debates about the East Asian model of aid apart from the more traditional Western models. However, only a handful of studies have examined donor behavior empirically. This study aims to assess the motives in the foreign aid allocations of China, Japan, and Korea as a group and as individual donors by methodically and empirically examining aid patterns and the East Asian model of aid. This research shows that the most important drivers of aid allocations of East Asian donor are economic, as opposed to political-strategic or humanitarian, which is viewed as typical for China, Japan, and Korea. Furthermore, this characteristic of valuing economic factors can be seen more clearly in Asia and other regions compared to in Africa. However, on an individual country level, economic motives are the primary determinants of aid allocations only for China. Japan prioritizes humanitarian factors over economic ones, and Korea does not reveal a clear pattern either way.

Key Words: East Asian model, Foreign aid, China, Japan, Korea

* Hyuk-Sang Sohn is a professor of the Graduate School of Public Governance and Civic Engagement and the vice president for External Cooperation at Kyung Hee University. His research interests are political economy of development, international development cooperation, development NGOs, and development evaluation.

* Seokwoo Kim is a professor of the Department of International Relations at the University of Seoul. His research interests are political economy of international trade, development cooperation and international negotiations.

* Changbin Woo (Correspondence) is a research professor in the Center for International Development Cooperation (CIDEC), Kyung Hee University. His research interests are public policy and international development cooperation.

This work was supported by the Ministry of Education of the Republic of Korea and the National Research Foundation of Korea under Grant (NRF-2018S1A3A2075117).

The Korean Journal of International Studies Vol.18, No.2 (August 2020), 123-144 
$\mathrm{T}$ he debate about the changing landscape of global foreign aid is becoming increasingly heated as a growing number of emerging donors are quietly offering alternatives to aid-receiving countries (Sato et al. 2011). The expansion of the international donor community in the development aid landscape adds further complexity to this picture, representing both a serious challenge and tremendous potential for recipients and donors alike (Jerve 2007). Especially in Asia, traditional donors such as Japan are no longer overwhelmingly dominant in terms of absolute volume. China increasingly is influential as an emerging donor, although the PRC's foreign aid is often characterized as 'rogue aid' as it is shaped mostly by its national interest rather than by the needs of developing countries (Dreher and Fuchs 2015). Recently, Korea has been recognized as a major donor country by the international community by joining the Development Assistance Committee (DAC) of the Organization for Economic Cooperation and Development as its 24th member.

There are numerous controversies regarding the development of an East Asian model of aid as a separate and different paradigm from the traditional Western aid model. Despite such interest and awareness, and a wide-ranging discussion on East Asian aid characteristics, there is almost no empirical analysis of the collective behavior of these East Asian donors. Multiple studies have analyzed China, Japan, and Korea individually for each country's decisions on foreign aid allocations, but only a few comprehensive analytic and descriptive studies on some of their behaviors related to foreign aid exist. There are several reasons for this, the primary one being the scarcity of observations with complete information. Compared to Japan and Korea, which are members of the OECD's DAC, it is difficult to find data on China, which is not a member. Even with these limitations, there is growing interest in the rise of China as a donor country and the viability of an East Asian model of aid.

In this light, this research will first analyze the aid allocations of East Asian donors as a group to identify features of their aid that might be deviating from the behavior observed of traditional Western donors. Analyses will also be conducted regionally, classifying recipients in Asia, Africa, and other areas. Furthermore, we will analyze each of the three East Asian donors individually. Whereas earlier descriptive studies on foreign aid decision making tended to view these East Asian donors as a uniform group distinct from the traditional Western model of aid, this study will show differences between each donor country by comparing the relative importance of their motives. Through such analyses, we aim for a comprehensive discussion of whether these East Asian donors on average are different from the traditional donors, and whether there are clear distinctions between individual donor countries. 
This paper is organized as follows. The next section will first review the literature on aid determinants and summarize claims and disputes regarding an East Asian aid model based around China, Japan, and Korea. The third section will introduce our research design, the data we use in detail, and our methods of analysis. The next section will present the results of our findings, first on the three donors as a group, followed by regional analyses, and subsequently on each of the three individual East Asian donors. In final section, this paper will conclude by discussing this research's implications and its limitations.

\section{LITERATURE REVIEW}

\section{AID ALLOCATION MOTIVES BY DONORS AND DONOR GROUPS}

Donors give foreign aid for various reasons. The decision to give aid cannot be attributed to a single factor, but rather to a complex combination of political, economic and social factors, and factors at home and abroad. Prior studies on foreign aid therefore have selected such factors as determinants and were generally fragmented due to the complexity of the interaction of those decision factors. Traditionally, views on foreign aid can commonly be divided into two theoretical approaches to explaining the motives informing aid allocations.

The first theoretical approach emphasizes the donor's interest (DI), based on the claim that countries regard foreign aid as a means of strategic foreign policy through which internal and external political and economic goals are reached. In other words, aid is provided to achieve strategic and military interests, improve national status in international society, and increase economic benefits through trade, investment, and resource acquisition (Maizels and Nissanke 1984; Alesina and Dollar 2000; Berthélemy and Tichit 2004; Younas 2008). The second argument asserts that the recipient's need (RN) is the primary decision factor for foreign aid: its real purpose is to promote the recipient country's political, economic, and social development, such as the recipient country's infrastructure, healthcare, education, democratization, and government systems (Hoeffler and Outram 2011; Neumayer 2003; Claessens et al. 2009).

Recently, there has been increased recognition of other motivations. Feeny, Hansen, Knowles, McGillivray, and Ombler (2019) argue that absorptive capacity -the ability of recipient countries to use aid effectively-is a more important motive than DI or RN. Domestic political incentives such as electoral strategy and party preferences are identified to shape the allocation of aid (Masaki 2018; Greene and Licht 2017). The formal independence of donor countries' aid 
agencies is found to have an effect on aid allocation decisions (Cardwell and Ghazalian 2018).

Furthermore, a particular group of countries are often observed to share some characteristics in their aid policies. Especially, donors with geographic proximity are posited to show similar characteristics, face similar internal and external restrictions, and pursue similar goals through their policies as they face similar internal and external situations. The Nordic welfare states of Sweden, the Netherlands, and Norway exhibit strong humanitarian motives (Alesina and Dollar 2000). Besides geographical location, countries with similar historical experiences are also expected to have similar aid policies. For example, the aid allocations of countries with a history of colonization, such as France, the United Kingdom, Portugal, and Belgium, are known to be influenced by their colonial past (Schraeder et al. 1998).

In addition, some countries, regardless of their geographical location or historical backgrounds, are conjectured to share political and strategic goals in foreign aid, such as promoting domestic security and economic benefits. In the study by Hoeffler and Outram (2011), the UK and Japan focused on recipient merit, unlike other countries. Dreher et al. (2011) found that older donors (OECD) showed a tendency to focus on RN, while emerging donors exhibit a much weaker tendency to do so compared to OECD DAC members.

\section{AN EAST ASIAN MODEL OF FOREIGN AID}

Recently, the East Asian model of foreign aid is becoming more popular as a paradigm differing from the Western aid model. Notably, the three countries of China, Japan, and Korea are often viewed as a united group by the outside world. According to one study, African governments see Chinese, Japanese, and Korean aid as similar in style and objective; for example, in the way they aim to secure natural resources, markets, and support in the international political arena (Cornelissen 2014).

Mostly, the claims for a unique East Asian model of foreign aid centered on China, Japan, and Korea are based on these countries' geographic proximity. More fundamentally, they share a common heritage of classical culture that stems from Confucianism. As these countries with cultural similarities compete with each other for reputation or benefits in a relatively confined region, a sort of peer group pressure is likely to work to encourage them to mirror one another. Subsequently, their foreign aid policies tend to converge. Yet, above all, the debate on an East Asian model of aid is based on the line of thought that foreign aid will be affected by a recently-shared, distinct experience of successful economic development. 
China, Japan, and Korea all share the experience of achieving successful economic development through a unique developmental model. So-called developmental states are known for having several characteristics in common: 1) a powerful government role; 2) export-oriented economic policies; and 3) an elite group formed around government officials taking the lead in designing and implementing policies (Woo-Cumings 1999). This common experience is a strong base for foreign aid decision making (Atkinson 2018). Confident in this model of success, these countries will try to spread the model to recipient countries. Furthermore, East Asian donor countries are likely to exhibit similar behavior; for example, of having a high concessional loan ratio while prioritizing their own economic gain.

Against this backdrop, scholars present various characteristics of the East Asian model of foreign aid that can generally be summarized as follows (Jerve 2010; Reilly 2012; Stallings and Kim 2016, 2017). First, these East Asian donors respond more to economic incentives; namely, trade, investments, and securing access to natural resources like oil and metals, without much regard to other factors. Confident in growth through industrialization, they intend to spread this model, of which foreign aid has an aspect of economic cooperation. Second, unlike Western foreign aid, East Asian aid does not have political conditions, nor does it come with political strings attached such as movement toward liberal democracy, governance, and human rights. This suggests that East Asian donors do not have much concern for the political situation in recipient countries, as economic aims become primary. Third, East Asian foreign aid is concentrated in Asian regions due to geographic proximity, shared cultures, and the sizable aid demand from Asian recipient countries.

However, some contend that these donor countries are wrongly reduced to an East Asian 'model'. First, China, Japan, and Korea are significantly different from each other in terms of the size of their economies, levels of development, and political institutions, which will affect their foreign aid policies and programs. Second, they went through individually varied experiences as an aid recipient and an aid donor. Korea's history as a donor is much shorter than that of Japan's. China's foreign aid does not incorporate the norms and standards of traditional donors. Third, the political circumstances of the three countries have been different. Japan and Korea seek to maintain their close relations with the United States for their security, while China is competing with the United States in various international political and economic areas.

Since there are political, economic, and social diversities among these three Asian countries, even the definition of aid can be different among them. Thus, "points of aid complementarity in Northeast Asia are harder to discern" (Kim and 
Potter 2012). There is no Asian model of aid if it is taken to mean one model (Jerve 2007). Fundamentally, some argue that aid motives cannot be generalized, as each country has its own agenda and there was no clear aid allocation standard (Schraeder et al. 1998; Pratt 1996; Riddell 2008).

Overall, the existence and traits of the East Asian model of aid is a controversial issue, and the model needs to be clarified through an evidence-based approach. Despite this need, there is almost no empirical analysis. While several studies have attempted to analyze China, Japan, and Korea individually for each country's motives behind foreign aid allocations (Cooray and Shahiduzzaman 2004; Fuchs and Rudyak 2019; Park \& Lee 2015), only a few studies have conducted comparative analyses of Japan and China (Furuoka 2017) or Japan and Korea (Kang et al. 2011). Yet, it is challenging to find a comprehensive comparative analysis of these three countries of their behaviors related to foreign aid. There are a few reasons for this, the primary one being the lack of data. Compared to Japan and Korea, which are members of the OECD DAC, it is difficult to find data on China, which is not a member. Despite these complications, there is growing interest in the rise of China as a donor country and an East Asian model of aid.

\section{RESEARCH DESIGN, DATA, AND METHODS}

\section{RESEARCH DESIGN}

Based on the above literature review, this study proposes a number of hypotheses about the aid determinants of East Asian donors as a group; that is, an East Asian model of aid. Few studies have addressed this question so far. We would expect East Asian donors as a group to provide more aid to countries crucial to the donors' interest (DI), especially economic gains like trade, investment, and securing natural resources. We will investigate whether the priority of economic incentives over others is the main characteristic of East Asian donors as a group. Thus, the first hypothesis is that the East Asian donors of China, Japan, and Korea, on average, give prior consideration to economic benefits in making foreign aid decisions.

Related to this, we are also interested in whether certain factors do not turn out to be statistically significant in East Asian donors on average, based on the debate on the aid allocation of these donors as a group. East Asian donors will consider neither a political-strategic advantage nor humanitarian motives such as the development of liberal democracy and good governance, unlike traditional Western donors. These considerations lead us to the hypothesis that donors' political-strategic interests measured by USAID aid volume do not play a 
statistically significant role in the aid allocations of East Asia's three donors. We also would not expect more aid to go to countries in higher need of aid, as measured by the Human Development Index (HDI), or more democratic countries as measured by the Freedom House's Political Rights (PR) and Citizen Liberties (CL) indices.

Next, we are also interested in whether the region plays a role in aid allocation by East Asian donors. In accordance with the existing literature examining the East Asian model of aid, we assume that specific characteristics of these East Asian donors will show regionality and appear noticeably more in Asian regions that are geopolitically crucial. We will investigate whether the priority of economic incentives over others is a salient feature of East Asian donors in Asian regions. The analysis will be conducted regionally, classifying recipients as Asian, African, or Other.

Moving away from investigating aid allocations by East Asian donors broadly as a group, or the existence of the so-called East Asian model of aid, we are also interested in whether donor countries have any individual differences. We assume that the analyses on the aid allocation by individual East Asian donors will show different results from the East Asian donors as a group. Thus, this research will further analyze the differences between each donor country to assess whether there are distinctions between individual donor countries. Through such analyses, we aim for a comprehensive discussion about East Asian donors, or the so-called East Asian model of aid apart from the Western model, and what are the differences between these individual donor countries.

$H_{1 a}$ : Three East Asian donors (China, Japan, and Korea) as a group focus on economic factors such as economic benefits from trade, investment, and securing natural resources when they allocate foreign aid.

$H_{l b}$ : Unlike traditional Western donors, China, Japan, and Korea as a group consider neither political-strategic advantage nor humanitarian motivations when they allocate foreign aid.

$\mathrm{H}_{2}$ : As East Asian donors mostly focus their aid on Asia, the above-mentioned characteristics will appear relatively remarkably in Asian regions compared to others.

$H_{3 a}$ : Each of the three East Asian donors individually focuses on economic factors, such as economic benefits from trade, investment, and securing natural resources when they allocate foreign aid.

$H_{3 b}$ : Unlike traditional Western donors, China, Japan, and Korea individually consider neither political-strategic advantage nor humanitarian motivations when they allocate foreign aid. 


\section{DATA COLLECTION AND VARIABLES}

This research aims to analyze the ODA allocation decision factors of East Asian donors as a group and the individual differences between China, Japan, and Korea. The research investigates a time period from 2000 to 2015, collecting data for the same period for all three countries to compare their decision factors regarding aid allocation. For Japan and Korea, the data on aid come from the OECD online statistics database, which provides information on DAC donor aid flows. Aid commitments are used as our dependent variable, as donors are presumed to exert more control over commitments than aid disbursements, which are dependent on recipient countries and implementing organizations. We lag commitments by one year in our specification in order to allow for commitments to be implemented.

In the case of China, an OECD DAC non-member, ODA-like estimates from AidData are utilized as our dependent variable. ODA-like is the flow of official financing, which is administered with the promotion of the economic development and welfare of developing countries as the main objective and is perceived to be concessional in character with a grant element of at least 25 percent (using a fixed 10-percent rate of discount). The following flow types should be categorized as "ODA-like" if they have "development intent": grants, technical assistance, interest-free loans, in-kind contributions of goods and services, and debt relief. As a rule of thumb, loans with a fixed interest rate of two percent or lower will have a grant element of at least 25 percent (Strange et al. 2015). For consistency, we use commitments rather than disbursements of aid as the above-mentioned cases of Japan and Korea.

AidData is a qualified research institution that collects data on emerging donors such as China, for which public data is challenging to obtain compared to its importance (Tierney et al. 2011). AidData has recently been utilized in numerous academic publications (Dreher et al. 2011; Dreher and Fuchs 2015; Hernandez 2017). AidData's data is verified in stages using TUFF (Tracking Underreported Financial Flows) methodology. It codifies a set of open-source data collection procedures that make it possible to identify information about officially financed projects that are not voluntarily or systematically recorded through international reporting systems. Projects are identified first through collecting donors' official data and data from websites and press sources, and then targeted searches are conducted for projects initially identified during the first stage (Strange et al. 2015). For this research, partly missing data such as country name is filled in through research, and currencies other than U.S. dollars are converted to USD.

Additionally, we face a potential sample selection problem, as not all donors 
give aid to all countries. In other words, when a country has not received aid from any of the three donors, the aid is reported as zero. We, therefore, focus on allocation without correcting for selection, based on studies which argue that the allocation equation is independent of the selection equation (McGillivray 2002; Berthélemy and Tichit 2004; Hoeffler and Outram 2011).

Variables included in this research as a donor country's economic gain are trade volume, foreign direct investment (FDI), and energy production volume. The trade volume, FDI between donor and recipient countries, and energy production of a recipient country are the main economic benefits through foreign aid contributions. For this, data are collected from the World Bank, OECD, UNCTAD (UN Conference on Trade and Development), and EIA (US Energy Information Administration).

Trade volume indicates the size of trade between each country, combining import and export trade value in thousands of U.S. dollars for various product groups by the country. FDI indicates outward foreign direct investment flows, the value of cross-border direct investment transactions from the economy during a year, by the destination country. We obtain FDI data for Japan and Korea from OECD and China from UNCTAD. The data for China do not include Hong Kong, Macao, and Taiwan. Total energy production is measured by quadrillion BTUs, including the production of petroleum (crude oil and natural gas plant liquids), dry natural gas, coal, and the generation of nuclear, hydroelectric, and non-hydroelectric renewable electricity. Based on these variables, trade volume, FDI, and recipient's energy production are expected to show a positive correlation with ODA aid volume.

Besides economic factors, USAID aid volume to recipient countries of interest is considered as an important political-strategic factor of the donor's national interest. While military aid, security alliances, and UN General Assembly voting records are often used as political-strategic factors, this research adopted USAID aid volume as a surrogate variable, in consideration of East Asia's geopolitical circumstances. East Asian donors' relationship with the United States is distinct in that Japan and Korea are much concerned with their alliance relationship with the United States due to the military threat from North Korea. In contrast, China stands in opposition, competing with the United States. ${ }^{1}$

\footnotetext{
${ }^{1}$ Finding an appropriate proxy for political-strategic factors is a challenging task. As for UN voting, bilateral pressure becomes worthwhile for the great powers only on very important issues (Keohane, 1965). Alesina and Dollar (2000), using votes as a proxy for political factors, admit that many UN votes are not very important, per se. A number of other variables have been tried as proxies for the political factor, and USAID aid volume is used as proxy variables at times for political influence (Thapa and Mehta, 1991). It is expected that the amount of Japanese and Korean ODA contributions
} 
A nation's economic level is commonly measured by GNI per capita, but here we are using the Human Development Index (HDI). Developed to overcome the limits of existing economic indices, HDI is a more comprehensive consideration of welfare than GNI per capita. It measures the degree of human development on three levels: health, education, and standard of living. China, Japan, and Korea's ODA contribution volumes are expected to be larger with recipient countries with lower HDI, if they pursue the recipient country's development.

Also, it is expected that aid will be provided to countries with democracy and political freedom if donors consider the recipients' political and social rights. The degree of democratization is, therefore, considered as a humanitarian factor variable, and the Freedom House's Political Rights (PR) index is used. It is expected that the ODA contribution volume from China, Japan, and Korea would increase with a higher democracy index of recipients. The population is also added as a control variable to estimate the size of recipient countries.

Some of the variables, such as trade volume, FDI, energy production volume, USAID aid volume, and population, are logarithm transformed to reduce heteroscedasticity. It is well known that reducing the variance of variables through logarithm transformation leads to more efficient regression models. In addition, the coefficient on the logarithm of the predictor denotes the elasticity of the dependent variable with respect to the predictor variable.

The following table shows descriptive statistics of the included variables in the empirical analyses.

Table 1. Variables and Descriptive Statistics

\begin{tabular}{c|c|c|c|c}
\hline & Mean & $\begin{array}{c}\text { Standard } \\
\text { Deviation }\end{array}$ & Minimum & Maximum \\
\hline Economic & & & & \\
\hline Trade & 12.162 & 2.468 & 4.652 & 19.662 \\
\hline FDI & 19.700 & 2.270 & 2.303 & 26.396 \\
\hline Energy & 11.187 & 3.238 & -2.303 & 18.352 \\
\hline Political-strategic & & & & \\
\hline USAID & 17.597 & 2.139 & 5.704 & 23.368 \\
\hline Humanitarian & & & & .878 \\
\hline HDI & .605 & .138 & .257 & 14.000 \\
\hline Freedom & 8.107 & 3.363 & 2.000 & \\
\hline Control & & & & 14.126 \\
\hline Population & 9.087 & 1.993 & 2.243 & \\
\hline
\end{tabular}

would be positively correlated with USAID aid volume, while China's ODA contribution would show a negative correlation with USAID aid volume. 


\section{METHOD OF ANALYSIS}

The panel dataset enables us to come up with more consistent estimates of the parameters of interest than cross-sectional data, which in turn allows for the construction and testing of more complex models. In general, a panel data set gives more information, more variability, and more degrees of freedom with higher efficiency (Harrigan and Wang 2011). There are several methods of examining the relationship between aid and its determinants based on the panel data methods. Generally, a panel dataset can be estimated in three ways, OLS, fi xed effects (FE), or random effects (RE).

The pooled OLS model assumes that there would be no individual-specific effects. The fixed-effect model assumes that the individual-specific effects exist but fix them. In the random-effect model, these effects are expected to exist and be random. To find out which estimation method would be the most appropriate, we perform Joint $\mathrm{F}$ tests to test the fixed effects model versus the OLS model. Hausman random effect test is applied to test the fixed effects model versus the random effects model. Breusch-Pagan (Lagrangian Multiplier) test is utilized to test the RE model versus the OLS model.

The pooled OLS procedure examines the relationship between the provision of foreign aid and determinants. The pooled OLS analysis is based on the equation

$$
A I D_{i t}=a+\beta_{1} X_{i t-1}+\beta_{2} X_{i t-1} \ldots+\varepsilon_{i t-1}
$$

where $\alpha$ is the common intercept, $\beta$ is the slope coefficient, and $\mathcal{E}$ the is error term. All variables on the right-side are lagged one year compared to dependent variables. In this model, the four slope coefficients are estimated without taking into account any unobservable effects.

The unobserved effects method incorporates unobservable recipient-specific effects, controlling for the time-invariant recipient

$$
A I D_{i t}=a_{0}+a_{i}+\beta_{1} X_{i t-1}+\beta_{2} X_{i t-1 \ldots}+\varepsilon_{i t-1}
$$

where $a 0$ is the common intercept, and $a i$ is the recipient dummy variable. The recipient-specific effects are various socio-political and economic aspects in the recipient county $i$. All variables on the right-side are lagged one year compared to dependent variables as before. They pertain to the aid recipients' historical background, their geographical location and demographic situation, their geopolitical clout, and potential economic and business attractiveness.

Regarding the analysis process, we first analyzed the aid allocations of East Asian donor as a group (2,968 samples) to identify features of their aid that might 
be deviating from the traditional behavior observed by Western donors. This analysis will also be conducted regionally, categorizing the recipients into Asia, Africa, and Other regions based on their geographic location. More specifically, this study analyzes 826 samples in Asia, 1,167 in Africa, and 975 in Other Regions. Next, we will analyze the individual aid allocations China (662), Japan (1,624), and Korea (682) separately, comparing the relative importance of their motives.

\section{RESULTS}

\section{AID ALLOCATIONS OF THE THREE EAST ASIAN DONORS AS A GROUP}

As a preceding step to identifying a causal relationship, a correlation analysis is conducted to verify the correlation between independent variables, dependent variables, and control variables. The following table shows the correlation matrix. When it comes to the freedom index, the sign is reversed, so that the higher value represents a higher degree of freedom.

Table 2. Correlation Matrix

\begin{tabular}{crrrrrrrr}
\hline & ODA & Trade & FDI & Energy & USAID & HDI & Freedom & Pop \\
\hline ODA & 1.0000 & & & & & & & \\
Trade & 0.3092 & 1.0000 & & & & & & \\
FDI & 0.2294 & $0.6156^{*}$ & 1.0000 & & & & & \\
Energy & 0.1081 & 0.6240 & $0.3199^{*}$ & 1.0000 & & & & \\
USAID & 0.2543 & 0.2940 & $0.1972^{*}$ & $0.2143^{*}$ & 1.0000 & & & \\
HDI & -0.1319 & -0.3008 & $0.1581^{*}$ & $0.3098^{*}$ & $-0.2174^{*}$ & 1.0000 & & \\
Freedom & -0.1045 & -0.0829 & 0.0204 & $-0.2188^{*}$ & $-0.1935^{*}$ & $0.2753^{*}$ & 1.0000 & \\
Pop & 0.3562 & 0.6234 & $0.3666^{*}$ & $0.3666^{*}$ & $0.5793^{*}$ & $-0.1532^{*}$ & $0.3809^{*}$ & 1.0000 \\
\hline
\end{tabular}

* $p<.05$

Empirical results from the pooled OLS analysis, the fixed effects model, and the random effect model are reported in Table 3.

In the pooled OLS model, which includes all three donor countries, four variables are shown to have a correlation with aid with statistical significance at the 0.05 level. Specifically, two economic motivations (bilateral trade and energy production volume) and two other variables (HDI and population) are shown to have a statistically significant association with aid. The donors allocate more aid to their trading partner countries, those with less energy production, poorer 
countries with lower HDI, and those with higher population.

In the second model of fixed effects (FE), only one variable, trade, is shown to have a statistically significant relationship to aid. Donors allocate more aid to their trading partner countries. In the random effects model (RE), three variables are shown to have a correlation with statistical significance at the 0.05 level: trade, HDI, and population.

Table 3. Analysis of Foreign Aid of Three East Asian Donors as a Group

\begin{tabular}{l|c|c|c}
\hline & Pooled OLS & FE & RE \\
\hline Economic & & & $.214^{* *}$ \\
\hline Trade & $.194^{* *}$ & $(.025)$ \\
\hline FDI & $(.022)$ & -.002 & .003 \\
\hline Energy & $\left(.009^{* *}\right.$ & $(.004)$ & $(.004)$ \\
\hline Political-strategic & $-.004)$ & .015 & $-.057^{*}$ \\
\hline USAID & $(.013)$ & $(.031)$ & $(.021)$ \\
\hline Humanitarian & & & .025 \\
\hline HDI & $.042^{*}$ & $(.021$ & $(.026)$ \\
\hline Freedom & $(.018)$ & & $-1.99^{* *}$ \\
\hline Control & & .390 & $(.440)$ \\
\hline Population & $\left(.1 .89^{* *}\right.$ & $(.756)$ & .009 \\
\hline $\mathrm{N}$ & $(.004)$ & $(.012$ & $(.017)$ \\
\hline
\end{tabular}

${ }^{* *} p<.01, * p<.05$

Hausman tests and F-tests reveal that the fixed effects model is the best estimation method. In the fixed effects model, East Asian donors on average consider neither political-strategic advantage nor humanitarian motivations when they make decisions on foreign aid. The foreign aid of East Asian donors as a group responds only to the economic incentives of trade. Hypothesis 1a and $1 b$ are accepted; the three East Asian donors as a group focus on economic factors and they consider neither political-strategic advantage nor humanitarian motivations.

The coefficient on the logarithm of trade is approximately 0.3 in the fixed effects model. It indicates that if trade increases by one percent, the three donors increase their aid by 0.3 percent, on average, as the coefficient on the logarithm 
of variables denotes the elasticity of aid with respect to variables in the regression model. Additionally, concerning population as a control variable, we cannot find the so-called "small country bias" that recipients with a smaller population receive more aid.

\section{FOREIGN AID ALLOCATIONS OF EAST ASIAN DONORS BY RECIPIENTS' REGION}

Next, the aid of the three donors is analyzed regionally in terms of Asia, Africa, and Other. We apply the pooled OLS model, fixed effects model, and random effects model separately to each of the three regions of East Asian donors' aid allocation. Joint F-tests and Hausman tests show that the RE model is the best estimation method in the case of foreign aid to African recipients, while in the case of aid to Asia and Other recipients, the FE model is the best. Findings on each East Asian donors individually from the fixed effects (FE) model and the random effects (RE) model are presented in Table 4.

Table 4. Analysis of Foreign Aid of Three East Asian Donors by Recipients' Regions

\begin{tabular}{l|c|c|c|c|c|c}
\hline & \multicolumn{2}{|c|}{ Asia } & \multicolumn{2}{c}{ Africa } & \multicolumn{2}{c}{ Other } \\
\hline Economic & FE & RE & FE & RE & FE & RE \\
\hline Trade & & & & & & \\
\hline FDI & $.168^{*}$ & $.171^{* *}$ & $.298^{* *}$ & $.269^{* *}$ & $.245^{* *}$ & $.142^{*}$ \\
& $(.064)$ & $(.057)$ & $(.039)$ & $(.036)$ & $(.061)$ & $(.045)$ \\
\hline Energy & .012 & $.027^{* *}$ & -.011 & -.007 & -.010 & -.011 \\
\hline Political-strategic & $(.011)$ & $(.009)$ & $(.007)$ & $(.007)$ & $(.008)$ & $(.007)$ \\
\hline USAID & -.014 & $-.091^{* *}$ & .009 & $-.053^{\dagger}$ & .004 & $-.037(.037)$ \\
\hline Humanitarian & $(.068)$ & $(.042)$ & $(.047)$ & $(.028)$ & $(.053)$ & \\
\hline HDI & -.085 & -.015 & -.088 & .025 & .027 & .032 \\
\hline Freedom & $(.087)$ & $(.061)$ & $(.059)$ & $(.045)$ & $(.048)$ & $(.036)$ \\
\hline Control & -.981 & $-2.675^{* *}$ & -1.516 & $-2.63^{* *}$ & -.373 & $-1.802^{*}$ \\
\hline Population & $(1.577)$ & $(1.091)$ & $(1.28)$ & $(.734)$ & $(1.172)$ & $(.875)$ \\
\hline $\mathrm{N}$ & .033 & .039 & .023 & .035 & -.071 & .002 \\
\hline & $(.071)$ & $(.038)$ & $(.042)$ & $(.024)$ & $(.056)$ & $(.028)$ \\
\hline
\end{tabular}

${ }^{* *} p<.01,{ }^{*} p<.05,{ }^{+} p<.1$ 
In Asia, economic factors such as trade, FDI, and energy are associated with aid, as well as the humanitarian factors of HDI and population in the RE model. In the FE model, which is a better-fitted estimation by Hausman test, correlations between aid and trade as an economic factor, along with population level, is statistically significant at the conventional level. No other humanitarian and political-strategic variables are related to aid, even at a statistical significance level of 0.1. Thus, East Asian donors as a group respond mostly to the economic incentives of trade in Asia.

In Africa, trade is also shown to have a correlation with aid in the FE model. In the RE model, trade is shown to have a relationship to aid at a statistical significance of 0.01 . However, trade is not the only factor that has a significant correlation with aid in the RE model. HDI also is statistically significant in association with aid, indicating that East Asian donors provide aid more often to more impoverished recipients in Africa. In Africa, East Asian donors as a group respond not only to economic incentives but also to humanitarian motivations. Additionally, energy production volume is negatively associated with aid at a statistical significance level of 0.1 .

In other regions, East Asian donors as a group provide aid for economic and humanitarian motives in the RE model, which seems very similar to the results in Africa. In the FE model, only trade as an economic motive is statistically significantly correlated. Both of the results of the RE and FE models in other regions appear very similar to those in Africa. Yet, in the case of Other regionsunlike in Africa-the FE model is a better-fitted one, in which only economic incentives are shown to be statistically significant. Thus, in other regions, it can be said that East Asian donors respond mostly to economic incentives without much regard to other factors. ${ }^{2}$

\section{FOREIGN AID ALLOCATIONS OF INDIVIDUAL EAST ASIAN DONORS}

Turning to the analysis of the foreign aid of each of the three East Asian donors, we also applied the pooled OLS model, fixed effects model, and the random effect model separately to each of the three East Asian donors' aid allocations. After conducting joint F-tests, Hausman test, and Breusch-Pagan (Lagrangian Multiplier) tests, we find that the RE model is the best estimation method in the case of China's foreign aid, while the FE model works best for Japan and Korea.

\footnotetext{
${ }^{2}$ Additionally, although it seems as though the beta coefficients of Asia are lower than those of Africa and Other regions, direct comparison between beta coefficients of each model may potentially yield misleading results. We cannot test for a difference in the parameters when the aid estimations are made over different samples, or when the aid equations are estimated separately (Hoeffler and Outram 2011).
} 
The findings on individual East Asian donors from the fixed effects (FE) model and random effects (RE) model are presented in Table 5.

Table 5. Analysis of Individual Foreign Aid Allocations of East Asian Donors

\begin{tabular}{l|c|c|c|c|c|c}
\hline & \multicolumn{2}{|c|}{ China } & \multicolumn{2}{c|}{ Japan } & \multicolumn{2}{c}{ Korea } \\
\hline Economic & $\mathrm{FE}$ & $\mathrm{RE}$ & $\mathrm{FE}$ & $\mathrm{RE}$ & $\mathrm{FE}$ & $\mathrm{RE}$ \\
\hline \multirow{2}{*}{ Trade } & & & & & & \\
\hline \multirow{2}{*}{ FDI } & $.475^{* *}$ & $.317^{* *}$ & -.051 & .029 & .112 & $.105^{*}$ \\
& $(.116)$ & $(.068)$ & $(.043)$ & $(.035)$ & $(.089)$ & $(.059)$ \\
\hline \multirow{2}{*}{ Energy } & .002 & $.018^{\dagger}$ & -.003 & -.000 & $.015^{*}$ & $.028^{* *}$ \\
\hline Political-strategic & $(.013)$ & $(.011)$ & $(.005)$ & $(.005)$ & $(.008)$ & $(.007)$ \\
\hline USAID & -.054 & $-.069^{\dagger}$ & -.030 & $-.064^{* *}$ & .033 & -.016 \\
& $(.069)$ & $(.037)$ & $(.029)$ & $(.023)$ & $(.057)$ & $(.039)$ \\
\hline Humanitarian & -.082 & -.019 & .005 & .037 & $.111^{\dagger}$ & $.128^{*}$ \\
\hline HDI & $(.094)$ & $(.058)$ & $(.031)$ & $(.027)$ & $(.061)$ & $(.049)$ \\
\hline \multirow{2}{*}{ Freedom } & -.693 & $2.66^{*}$ & -.606 & $-.869^{\dagger}$ & $2.427^{\dagger}$ & -.113 \\
& $(1.778)$ & $(.862)$ & $(.676)$ & $(.507)$ & $(1.356)$ & $(.887)$ \\
\hline Control & -.067 & .015 & $.048^{*}$ & $.035^{\dagger}$ & .072 & .009 \\
\hline Population & $(.075)$ & $(.032)$ & $(.028)$ & $(.020)$ & $(.055)$ & $(.032)$ \\
\hline $\mathrm{N}$ & & & & & & \\
\hline
\end{tabular}

${ }^{* *} p<.01,{ }^{*} p<.05,{ }^{\dagger} p<.1$

China is mainly focused on trading partners, whether in the FE method or RE method. In the FE model, China is mostly focused on the economic incentives of trading partners, with the highest elasticity of almost 0.5 percent, which indicates that if trade increases by one percent, China increases its aid by 0.5 percent. In the RE model, still focused on trading partners with the elasticity over 0.3 percent, China's aid is positively associated with HDI. China provides aid to countries with higher HDI, indicating China does not weigh up humanitarian motives. Rather, China responds inversely to them. Chinese aid allocations also correlate with FDI, another economic factor, at a statistical significance of 0.1. In addition, China's aid is negatively associated with energy production, at a 0.1 statistical significance level.

In the case of Japan in the RE model, a negative correlation between aid and energy production volume is statistically significant at the conventional level. When considering the relations with aid at a statistical significance level of 0.1 , 
humanitarian factors such as freedom and HDI are shown to be related to aid as expected. In the FE model, which is a better-fitted estimation by Hausman test, population size and level of freedom are relatively strongly associated with aid, which indicates that more aid went to those countries with a larger population and with a higher level of freedom. The level of freedom is represented by the index from Freedom House.

Korea in the RE model shows a mixed pattern of aid allocation behavior, with diverse motivations. Like China, Korea provides more aid to trading partners, and even to countries with more FDI. Korea provides more aid to countries receiving more aid from the United States, which could indicate that Korea considers political-strategic relations with other countries-as reflected in the amount of USAID aid-as a primary factor in determining aid allocation. In the FE model, Korea is mostly focused on FDI, indicating the influence of economic incentives, and tends to give more aid to countries receiving more aid from the United States at a statistical significance level of 0.1. Remarkably, Korea gives more aid to countries with a higher HDI, which implies that Korea is concerned about aid effectiveness and gives more aid to more highly developed recipient countries.

\section{DISCUSSION AND CONCLUSIONS}

One of the characteristics of East Asian donors pointed out by previous literature is that economic factors are important determinants of foreign aid. While FDI and energy production do not show a correlation, trade is correlated and statistically significant in the combined model of all three donors; therefore, Hypothesis 1a is accepted. As the variables of political-strategic or humanitarian motives do not show a statistically significant correlation with the aid allocation of three donors as a group, Hypothesis $1 b$ is also accepted. Thus, based on the results, one of the key findings of this study is that East Asian donors as a group mostly focus on economic factors, with less consideration for political-strategic advantage or humanitarian relief.

Second, focusing on region, it is assumed that East Asian donors place a higher emphasis on economic motives in greater Asia, where their aid is most concentrated. In Asia, East Asian donors as a group respond mostly to the economic incentives of trade, with no other humanitarian and political-strategic variables correlating with aid. The cases in Asia reveal that East Asian donors place rather a higher emphasis on economic motives in Asia, especially compared to the cases in Africa, where humanitarian and economic motives are 
important. Thus, the result demonstrates that the Hypothesis 2 is supported, as the above-mentioned characteristics of East Asian donors appear in Asia but not in Africa.

Third, on the individual donor level of the East Asian model, the priority of economic incentives is not as remarkable as it is for the whole group, with the exception of China. As to China's aid, trade maintains a robust and positive correlation with aid. It is also positively associated with HDI, indicating that China gives more aid to countries with higher HDI, contrary to humanitarian motivation. However, no correlation with economic factors is found in the case of Japan. Japan is shown to consider the importance of democratic factors, not economic incentives. Korea's aid shows a statistically significant correlation with FDI, an economic variable. Korea's aid is also shown to be associated with USAID and HDI at a statistical significance level of 0.1. Thus, Hypothesis $3 a$ and $3 \mathrm{~b}$ are not accepted.

Taken together, the most critical driver of aid for China, Japan, and Korea as a collective group proves to be trade, without much regard to the other factors. However, as individual donors, China prioritizes economic factors, Japan does not exhibit these characteristics at all, and Korea does not reveal a clear pattern either way. Especially, Japan deviates considerably from the typical characteristic of the East Asian donors in the sense that it responds mostly to humanitarian motivations. As one scholar put it, "Japan's foreign aid system has been gradually Westernized and has converged with other DAC countries" (Huang, 2016). Korea shows a mixed pattern, responding to political-strategic factors as well as economic motives.

East Asia is very diverse, and China, Japan, Korea, and other East Asian regions thus have many differences. China, Japan, and Korea are each unique in the size of their economy, their economic development level, and their political system. As mentioned before, each of these countries has varying experiences as donors and recipients. The political and security circumstances of the three countries are also very different. The systems and laws that dictate foreign aid are dissimilar, too. Considering that these differences influence foreign aid decision and execution, aid flows from these East Asian donors also shows different patterns.

The idea that these countries with such different levels of development, structure, international political roles, foreign aid experiences, systems, and policies may share a model of aid with common characteristics may be simplistic in light of this complex reality. Then, why is there discussion about the East Asian model of aid separate from that of Western countries, based on characteristics shared by all these countries? This seems to be more related to an attempt to 
understand China, whose foreign aid does not embrace traditional foreign aid norms and standards, and whose significance in global aid is rising with its recent sudden emergence. There have been mixed attempts to generalize and criticize China's aid characteristics as representative of all of Asia, along with attempts to justify Chinese aid behaviors.

These thoughts can be traced back primarily to the stereotypes of East Asian developmental states. In the process of understanding the successful development of East Asian countries, there has been a tendency to regard them as having unique and exemplary Asian values that apply to the region and by exaggerating East Asia's distinct features. However, these attempts can be misleading about an individual country's policy designs through overgeneralization. According to Sen (1997), "Asian values," especially authoritarianism, has no real significance and is not even particularly Asian. Also, in foreign aid, rather than clinging to an 'Asian model' based on 'Asian values,' the differences between Asian countries' aid decision making need to be understood and assessed individually according to each country's circumstances and aid allocation policies.

Our study is meaningful as an attempt to methodically and empirically validate the East Asian model of foreign aid using ODA data on Japan and Korea from the DAC and data from AidData on China-on which no standardized ODA data exists. With common data samples, the three donors' aid allocation patterns were rigorously compared, and regionally classified and analyzed.

Our research is not without its limitations. At a fundamental level, we use the same variables and the same timeframe to compare countries that began giving foreign aid at different times and from different contemporary motives. Methodologically, our research also does not consider the selection issue of how donors choose recipients, focusing instead on allocations rather than donors' overall behaviors. Further research is needed to overcome these limitations and expand the discussion on the existence and significance of the East Asian model of aid.

\section{REFERENCES}

Alesina, Alberto and David Dollar. 2000. "Who Gives Foreign Aid to Whom and Why?” Journal of Economic Growth 5(1), 33-63.

Atkinson, Joel. 2018. "The Real East Asian Aid Model: Development Assistance as an Instrument of Comprehensive Security in Japan, South Korea and 
Taiwan." Development Policy Review36(3), 265-284.

Berthélemy, Jean-Claude and Ariane Tichit. 2004. "Bilateral Donors' Aid Allocation Decisions-A Three-dimensional Panel Analysis." International Review of Economics \& Finance 13(3), 253-274.

Cardwell, Ryan and Pascal L. Ghazalian. 2018. "The Effects of Aid Agency Independence on Bilateral Aid Allocation Decisions.” World Development 106, 136-148

Claessens, Stijn, Danny Cassimon and Bjorn Van Campenhout. 2009. "Evidence on Changes in Aid Allocation Criteria." The World Bank Economic Review 23(2), 185-208.

Cooray, Nawalage S. and Md Shahiduzzaman. 2004. "Determinants of Japanese Aid Allocation: An Econometric Analysis." International Development Series 4, 2-19.

Cornelissen, Scarlett. 2014. Asian Development Assistance Models-The Case of Africa. Paper presented at the JICA Conference on Japan and the Developing World: Sixty Years of Japan's Foreign Aid and the Post-2015 Agenda (November).

Dreher, Axel and Andreas Fuchs. 2015. "Rogue Aid? An Empirical Analysis of China's Aid Allocation." Canadian Journal of Economics/Revue Canadienne d'économique 48(3), 988-1023.

Dreher, Axel, Peter Nunnenkamp and Rainer Thiele. 2011. "Are 'New' Donors Different? Comparing the Allocation of Bilateral Aid Between NonDAC and DAC donor countries." World Development 39(11), 1950-1968.

Feeny, Simon, Paul Hansen, Stephen Knowles, Mark McGillivray and Franz Ombler. 2019. "Donor Motives, Public Preferences and the Allocation of UK Foreign Aid: A Discrete Choice Experiment Approach.” Review of World Economics, 1-27.

Furuoka, Fumitaka. 2017. "Determinants of China's and Japan's Foreign Aid Allocations in Africa." African Development Review 29(3), 376-388.

Fuchs, Andreas and Marina Rudyak. 2019. "The Motives of China's Foreign Aid." In Ka Zeng ed., Handbook on the International Political Economy of China. Edward Elgar Publishing, 392-410.

Greene, Zachary D. and Amanda A. Licht. 2018. "Domestic Politics and Changes in Foreign Aid Allocation: The Role of Party Preferences." Political Research Quarterly 71(2), 284-301.

Hernandez, Diego. 2017. "Are 'New' Donors Challenging World Bank Conditionality?” World Development 96, 529-549.

Harrigan, Jane and Chengang Wang. 2011. "A New Approach to the Allocation of Aid Among Developing Countries: Is the USA Different from the Rest?" 
World Development 39(8), 1281-1293.

Hoeffler, Anke and Verity Outram. 2011. "Need, Merit, or Self - Interest-What Determines the Allocation of Aid?" Review of Development Economics 15(2), 237-250.

Huang, Meibo. 2016. "Policies and Practices of China's Foreign Aid: A Comparison with Japan.” In Kato Hiroshi, John Page, and Yasutami Shimomura eds., Japan's Development Assistance. London: Palgrave Macmillan, 135-148.

Jerve, Alf Morten. 2007. Asian Models for Aid: Is There a Non-Western Approach to Development Assistance? Summary Record of Seminar Held at the Christian Michelsen Institute, Oslo (December 2006).

Kang, Sung Jin, Hongshik Lee and Bokyeong Park. 2011. "Does Korea Follow Japan in Foreign Aid? Relationships Between Aid and Foreign Investment." Japan and the World Economy 23(1), 19-27.

Kim, Hyo-Sook and David M. Potter. 2012. Foreign Aid Competition in Northeast Asia. Sterling, VA: Kumarian Press.

Keohane, Robert Owen. 1965. "Political Influence in the General Assembly." Int'I Conciliation 36, 1.

Masaki, Takaaki. 2018. "The Political Economy of Aid Allocation in Africa: Evidence from Zambia." African Studies Review61(1), 55-82.

Maizels, Alfred and Machiko K. Nissanke. 1984. "Motivations for Aid to Developing Countries." World Development 12(9), 879-900.

McGillivray, Mark. 2002. "Modelling Foreign Aid Allocation." Helsinki/ UNU/WIDER. Mimeo.

Neumayer, Eric. 2003. "Do Human Rights Matter in Bilateral Aid Allocation? A Quantitative Analysis of 21 Donor Countries." Social Science Quarterly 84(3), 650-666.

Park, Bokyeong and Hongshik Lee. 2015. "Motivations for Bilateral Aid Allocation in Korea: Humanitarian, Commercial, or Diplomatic?" Asian Economic Papers 14(1), 180-197.

Pratt, Cranford, ed. 1996. Canadian International Development Assistance Policies: An Appraisal. McGill-Queen's Press-MQUP.

Reilly, James. 2012. "A Northeast Asian Model of ODA? Comparing Chinese, Japanese and Korean Official Development Assistance." The Asia-Pacific, Regionalism, and the Global System, 216-35.

Riddell, Roger C. 2008. Does Foreign Aid Really Work? Oxford: Oxford University Press.

Sato, Jin, Hiroaki Shiga, Takaaki Kobayashi and Hisahiro Kondoh. 2011. "'Emerging donors' from a Recipient Perspective: An Institutional 
Analysis of Foreign Aid in Cambodia." World Development 39(12), 2091-2104.

Schraeder, Peter J., Steven W. Hook and Bruce Taylor. 1998. "Clarifying the Foreign Aid Puzzle: A Comparison of American, Japanese, French, and Swedish Aid Flows.” World Politics 50(2), 294-323.

Sen, Amartya. 1997. "Human Rights and Asian Values." New Republic 217(2-3), $33-40$.

Stallings, Barbara and Eun Mee Kim. 2016. "Japan, Korea, and China: Styles of ODA in East Asia.” In Kato Hiroshi, John Page, and Yasutami Shimomura eds., Japan's Development Assistance. London: Palgrave Macmillan, 135-148.

Stallings, Barbara and Eun Mee Kim. 2017. Promoting Development: The Political Economy of East Asian Foreign Aid. Boston, MA: Springer.

Strange, Austin M., Mengfan Cheng, Brooke Russell, Siddhartha Ghose and Bradley Parks. 2015. AidData's Methodology for Tracking Under-reported Financial Flows. Williamsburg, VA: AidData.

Thapa, Samanta B. and Dileep R. Mehta. 1991. "An Empirical Investigation of the Determinants of the Supply of Bank Loans to Less Developed Countries." Journal of Banking \& Finance 15(3), 535-557.

Tierney, Michael J., Daniel L. Nielson, Darren G. Hawkins, J. Timmons Roberts, Michael G. Findley, Ryan M. Powers, Bradley Parks, Sven E. Wilson and Robert L. Hicks. 2011. "More Dollars Than Sense: Refining Our Knowledge of Development Finance Using AidData." World Development 39(11), 1891-1906.

Woo-Cumings, Meredith. 1999. The Developmental State. New York, NY: Cornell University Press.

Younas, Javed. 2008. "Motivation for Bilateral Aid Allocation: Altruism or Trade Benefits." European Journal of Political Economy 24(3), 661-674. 